\title{
SIR DAVID BARRY'S EXPERIMENTS ON VENOUS RETURN
}

\section{G. S. BREATHNAGH}

ONE who has made, by way of experiment, even a minor addition to Harvey's brilliant elucidation of the circulation deserves a fate better than has befallen Sir David Barry. Barry was born in Co. Roscommon on 12 March 1780 , and served with the British forces in the Peninsular War, having joined the army as an assistant surgeon in 1806. His experiments on the return of blood to the heart, and the communications he made upon them, were the climax of the four years, from 1822 to 1826 , spent in the study of physiology and medicine at Paris. These researches earned for him the Fellowship of the Royal Society, but from I 826 onwards he seems to have deserted the laboratory and his interests were largely in the field of infectious diseases and public health. With Louis and Trousseau he visited Gibraltar in $1828-9$ to investigate an epidemic of yellow fever. After a visit to Russia in 1831, to study cholera, he was knighted; and later he served on a commission appointed to examine the medical charities in his native country. He died suddenly of an aneurism on 4 November 1835 , and were it not for Victor Robinson ${ }^{1}$ and Kenneth J. Franklin ${ }^{2}$ a name familiar in the nineteenth century might well be missing from the annals of cardiorespiratory physiology.

Although the relation between cardiac and pulmonary function remained obscure until the circulation was described by Harvey $(1628),{ }^{3}$ and Hooke $(\mathrm{I} 667)^{4}$ and Lower $(\mathrm{I} 66 \mathrm{~g})^{5}$ uncovered the first secrets of respiration, an association had been assumed from the days of Galen. As Sir Michael Foster ${ }^{6}$ pointed out, the Pergamene's experiments on artificial respiration were followed slavishly in De fabrica by Vesalius in 1543 and by Fabricius in De respiratione et ejus instrumentis (written 1599, published 1603 ), a treatise which, in Foster's words, is 'sheer Galenism'. That the failing heart could be restored in these experiments by artificial respiration was taken to indicate that respiration and life were synonymous and that inspiration in some way necessarily promoted the movement of blood through the pulmonary vessels; assumptions that were not challenged until Robert Hooke did so in 1667 . Hooke showed that, when multiple pleural perforations had been made over the surface of the lungs, 'a continual blast of air' through the trachea kept the animal alive.

Towards the latter end of this experiment a piece of the lungs was cut quite off; where it was observable, that the blood did freely circulate, and pass through the lungs, not only when the lungs were kept constantly extended, but also when they were suffered to subside and lie still. . . . The bare motion of the lungs, without fresh air, contributes nothing to the life of the animal .... it was not the subsiding or movelessness of the lungs that was the immediate cause of death, or of the stopping of the circulation of the blood through the lungs, but the want of a sufficient supply of fresh air. 


\section{S. Breathnach}

Hooke's contemporary, Richard Lower, may have been on the brink of the truth when he ligated the inferior vena cava just above the diaphragm and observed the animal after closing the chest, but he was more concerned with the peripheral than the central effects of the ligation in his eagerness to show that the brain through its nerves served to 'impart spirits to sustain the heart's movements'. 5

Experimental evidence, however, accumulated but slowly, and Harvey's belief in the vis a tergo as the motive force in the veins seems to have held unchallenged sway for almost a century until the first account of Barry's experiments was given before the Académie des Sciences in 1825. As was their custom with 'learned strangers', the Academicians appointed two Commissioners to report on Barry's demonstrations, and in presenting their assessment Baron Cuvier and Professor Dumeril referred to the historical background of the work. They remarked that Rudiger (whose name is not to be found in the Biographie Médicale) 'supposed that the blood was brought up with greater or less velocity, according as the lungs were more or less empty' and that Santorini, the Venetian anatomist ( $168 \mathrm{I}-1737)$, believed that 'a deeper and more rapid inspiration allowed a freer course to the blood in the lungs' (Barry). ${ }^{7}$ Recourse to experiment did not always give consistent answers. When in $1723 \mathrm{Morgagni}^{8}$ repeated Valsalva's direct inspection of the jugular veins in dogs his results, in this matter alone, he remarks, contradicted those of his master: Valsalva related detumescence of the exposed vein to inspiration, but Morgagni, laying a hand on the dog's abdomen in order to concentrate visually on the vein, saw the reverse. A decade later Stephen Hales ${ }^{9}$ measured the pressures in 'that part of the jugular vein that comes from the head' in a horse, a sheep and numerous dogs, but when he measured the lateral pressure in a supposedly unobstructed jugular vein in a dog the blood 'rose six inches, and on straining $9 \frac{1}{2}$ inches'.

By 1747 Haller was conversant with 'a certain consent or proportion between the pulse and respiration', and he listed among the 'secondary uses of respiration' its ability to 'excite a kind of flux and reflux in the blood'. ${ }^{10}$ Inspiration accelerated the venous return by 'the power of derivation', a neat but inconsequential phrase that was not clarified when the subject was taken up at length in Haller's Dissertation on the Motion of the Blood. ${ }^{11}$ The experiments on the movement of the blood in the veins, described in this monograph, were conducted with the assistance of Haller's pupil, Walstorf, and were copied four months later, allegedly, by 'M. Lamure who must have heard of them' from 'my friends in France, particularly M. de Raumur and M. de Sauvage', to whom Haller had communicated his results in April I 752. Lungs held in the expiratory position he found to be impassable to blood, which entered easily as soon as the lungs were inflated. In the same way injections could be seen to pass more freely from the pulmonary artery to the vein through expanded lungs. Although Haller actually speaks of the 'respiratory pulse' in the venae cavae, when he comes to 'the most difficult part of the work' he does not include the respiratory cycle among the 'causes producing all these differences in motions' of the blood. No new information was added until $182 \mathrm{I}$, when Magendie ${ }^{12}$ introduced a gumelastic sound into the jugular vein of a dog, passed it down into the right atrium, 


\section{Sir David Barry's Experiments on Venous Return}

and saw 'that the blood flowed from the extremity of the sound only in the moment of expiration'. He noted, too, that 'entirely analogous results were obtained by introducing the sound into the crural (femoral) vein, directing it towards the abdomen'. Nevertheless, although he was aware, like his predecessors, of the connection between inspiration and the quickening of the movement of the blood in the larger venous trunks, Magendie made no reference to the intrathoracic pressure gradient.

Nor was Barry the first in the theoretical field. Concluding their report on his work, Cuvier and Dumeril pointed out that

... the mere idea of the pressure of the atmosphere being the principal cause, was not first taken up by him. Many others had pointed out this even before Dr. Zugenbuhler, who has thought proper to address a claim of priority to the academy, putting in at the same time a dissertation De Motu Sanguinis per Venas, published in 1815. This author, however, although he recognizes the action of the pressure of the atmosphere, considers the heart as the first cause of the vacuum which is formed in the system. But M. Barry attributes the dilatation of the heart itself, and of its auricles, to the tendency to a vacuum which takes place in all the cavities of the chest during inspiration, demonstrating this action by positive experiments, whilst M. Zugenbuhler offers argument only in support of his opinion. (Barry, loc. cit.)

Zugenbuhler was not alone in his chagrin. James Carson ${ }^{\mathbf{1 3}}$ of Liverpool, in preparing the second edition of his An Inquiry into the Causes of Respiration, etc., the first edition of which had appeared in 18 I $_{5}$, complained bitterly of the 'sudden, extensive, and high reputation' obtained through the 'remarkably flattering report of Sir D. Barry's performance at the French Institute'. Barry, in fact, mentioned Carson's claim in his work, but was careful to include the unvarnished truth that Carson's circulatory doctrines, built around a vis a fronte arising 'in consequence of dilatation of the ventricles' by the elasticity of the lungs, were unsupported by direct experiment.

However, Carson's I 817 experiments on the resilience possessed by the lungs which showed itself by outward displacement of air through the trachea when the pleural cavities were opened (the visceral pleura being undamaged), had been transmitted to the Royal Society and printed in the Philosophical Transactions for 1820. ${ }^{14}$ Neatly as he sidestepped acknowledgement of Carson's influence, Barry cannot have eluded it-his contribution was, in essence, to apply the negative pressure, which the Liverpudlian had demonstrated to exist within the chest, to the heart and great vessels, particularly the thin-walled veins and atria. ${ }^{7}$ Barry argued thus:

... as it is an unalterable law, that all liquids in communication with an enlarging cavity will be pressed towards it, if exposed at the same time to atmospheric influence, it became presumable that blood would be forced into the thorax through the cavae during inspiration. ... .

... Having by these arguments (anatomical and clinical observations) and others now unnecessary to be recapitulated, brought my hypothesis thus far, I came to the following presumptive conclusions.

I. That a liquid such as water in an open-vessel being by means of a tube placed in direct communication with the cavity of one of the great veins within the thorax of a living animal, would be forced by atmospheric pressure to rise in the tube, and that the motion of the liquid within the tube would be regulated by the respiratory movements of the animal.

2. That the same phenomenon would be exhibited by establishing the same communication between the liquid and any of the cavities around the vein. 


\section{S. Breathnach}

Barry's first series of experiments was made on horses and dogs-and one donkey is mentioned. The animal was thrown on its right side and secured, the left jugular vein was exposed and ligated, and a flexible catheter (in the horse $10 \frac{1}{4}$ inches in length) was introduced into the vessel an inch below the ligature and pushed towards the heart as far as it would go. To the outer end of the catheter was attached a spiral tube which carried, at its distal end, a narrowing straight segment four inches in length, arranged at right angles to the core of the spiral. When the free point of the spiral tube thus prolonged was immersed in a solution of ferricyanide (Prussian blue) the liquid rose rapidly as soon as the operator removed his finger which previously had guarded the orifice. The blue solution moved through the spiral towards the heart during inspiration, and halted or returned slowly towards the cup during expiration. The respiratory cycle was in some animals audible; in others it was timed by placing a hand upon the ribs. By allowing air bubbles into the tube the progression of the fluid towards the heart during inspiration was made the more easily discernible. Blood seldom appeared in the tube, and then only during expiration, after which it was rapidly removed by the next inspiration. Barry openly admitted that he was not able to detect any connexion betwen the motions of the liquid and respiration while the horse was standing, a point that appealed to the sardonic Carson, who gleefully inferred that 'according to Sir D. Barry's doctrine, the blood of horses must not circulate when they are standing'. ${ }^{13}$ Similar experiments were carried out on the inferior vena cava in dogs, and it is regrettable that our investigator did not attend sufficiently to one of his observations. For in his later discussion of absorption he made the intrathoracic negative pressure all-powerful, pervading all veins in its effect, although he noticed that when the catheter was introduced into the femoral vein and pushed no further towards the heart, inspiration produced no effect upon the liquid in the cup.

The next step was to investigate the pressure in the pleural and pericardial sacs. Two problems had to be overcome: first, the danger of perforation of the lung or heart and, secondly, the provision of an adequate seal at the surface of the body to prevent ingress of air. Barry began by implanting a pointed metal tube, guarded externally by a small rubber bag, which was filled with a composition of lard and wax and secured by a ligature to the skin. Through a small hole in this bag a flexible catheter, having at its inner end the barrel of a quill in the side of which a slit had been made to act as a valve, was passed into the chest. By connecting the outer end of the catheter to a spiral tube the distal end of which was already immersed in a coloured fluid, it was plainly seen that the liquid was drawn into the chest during inspiration, but that it remained stationary or fell in the glass tube during expiration. Observations on the intrapleural pressures were made in the dog, but Barry had difficulty in avoiding rupture of the canine heart and his pericardial experiments were conducted on larger animals. In horses and in one donkey there was more than the respiratory rhythm to be observed for 'although the liquid invariably halted or descended (i.e. flowed back into the cup) during expiration there was an oscillation of the fluid upwards which seemed independent of respiration'. This 


\section{Sir David Barry's Experiments on Venous Return}

added indraught was masked in the general motion upwards of the liquid in the tube during inspiration, and nowadays it would be attributed to the suctionpump activity of the atrium produced by its prolongation during ventricular systole. ${ }^{15}$ From his opening note, however, Barry had declared himself a Harveian 'circulator' and denied suction power to the heart, quoting in fact De Motu ( 1628 ) in his defence: 'Neque verum est similiter quod vulgo creditur, cor, ullo suo motu aut distensione, sanguinem in ventricularis attrahere, dum enim movetur expellit etc.' Though it has to be conceded that Harvey believed that the venous blood was moved exclusively by the vis a tergo, it is noteworthy that he denied ventricular, as distinct from atrial, suction. After the experimental demonstration of the negative pressure within the pericardium in the donkey, a considerable quantity of the ferricyanide used in the experiment was found in the sac by Barry when the animal was opened. ${ }^{7}$

One further experiment in the living animal was devised by Barry. He divided the jugular vein in a horse and inserted a glass tube expanded in the middle of its course, so that when in place it formed a wide globe between the two ends of the vein. ${ }^{7}$ When the lightly tied ligatures on the vessel were opened the blood rushed rapidly through the globe. A small air bubble trapped in the upper segment of the globe made observation of the movement of the blood within possible, while a hand on the ribs indicated the phase of the respiratory cycle. 'Having once caught the proper light', the experimenter could see clearly the motion of the blood 'keeping exact time with the inspirations.' The synchronization was even more distinctly perceived than in the experiments using Prussian blue in the glass spiral for the animal's breathing was not hurried and there was no regurgitation during expiration. The entry of blood into the dilated bulb was not synchronous with respiration while the horse was standing, and Barry noted-in a variation of Magendie's experimental demonstration of the vis a tergo ${ }^{16}$ - that the flow was reduced by pressure on the carotid artery. When the horse was thrown, on the other hand, these smaller more rapid movements within the globe were obscured by those of respiratory origin. A clinical digression on the effect of posture on the jugular pulse, at this point in the monograph, is made the more piquant by a foreshadowing of the $a$ and $c$ waves in Mackenzie's jugular trace: 'the jugulars began to swell before the artery . . . but', Barry continues, 'they arrive at their acme at the moment that the artery strikes the finger'.

Barry $^{7}$ also described an artificial circulation made up of compressible and incompressible tubes, but it is difficult to discern from his description whether this investigation was purely theoretical or founded on data derived from actual experiments. It is certain, however, that he wrestled with the problem of the lesser circulation in a practical way. Galen's difficulty with the circulation, and his failure to suspect that the blood moved in a continuous circuit, arose from the fact that he denied-not without good reason, for such was his own experience-the possibility of ligating the pulmonary vessels, the veins particularly, without concomitant immediately fatal damage to contiguous structures. ${ }^{17}$ Indeed, the pulmonary vessels remained inaccessible to worth-while experiment until Cournand and Ranges in 1941 opened a new era in cardiology 


\section{S. Breathnach}

by their development of Forssman cardiac catheterization. ${ }^{18}$ It was by inspection alone that Lower ${ }^{5}$ had rediscovered what had been known to the ancients who named the veins entering the left atrium the arteriae venosae and Servetus, a century before him, had mentioned en passant in the ill-fated Restitutio Christianismi. It is thus no surprise to find Barry working on lungs removed at autopsy; and he succeeded in showing, by attaching one end of his spiral tube to a lung vein while the other was immersed in a glass of red wine and water, that the pulmonary veins behave as 'reservoirs ... from which the left heart can be supplied during the period when the lungs are least pervious', i.e. during expiration. This variable capacity of the pulmonary vascular bed has since been demonstrated in vivo by Schleier, ${ }^{19}$ although Sjostrand ${ }^{20}$ believes that it is the post-capillary venules rather than the large pulmonary veins which provide the reservoir effect.

The Memoir was followed by a Supplement which preceded the Report of the Commissioners, and Cuvier and Dumeril's favourable comments gave way in turn to a discursive account of Barry's views on Absorption. His experiments in this field were designed to prove his thesis, a corollary of his earlier work, that 'the application of a powerful cupping glass to a recently poisoned wound, would prevent the absorption of the poisonous matter'. ${ }^{7}$ These experiments with prussic acid, strychnine, the Javanese poison containing strychnine upas tieuté, and viper venom-in nearly all instances controlled-were of some practical value even if the interpretation placed upon them was unacceptable to his contemporaries as well as his successors. None the less they may here be passed over in favour of Barry's major conclusion:

From what we have seen in the Memoir and from what has been said in the Supplement it is evident that fluids whether moving through living, or through inert tubes, obey the laws of pressure and of gravitation and that in the quiescent living animal, the only demonstrable active powers employed by nature to propel the contents of the veins towards the heart, are-

First, the impulse given by the pressure of the heart itself, continued through, and propagated by the arteries. By this power the blood is sent into the situation where it can be most favourably acted upon by

Secondly, Atmospheric pressure, diminished or entirely taken off around the cardiac ends of the venous tubes during the expansion of the chest, but unaltered and entire around every other part of their surface, opposed only by the gravity of the fluid acted upon.

Thirdly, Gravitation, when the heart is relatively the most depending point, or when this power is acting with the pressure of the heart's contraction upon the base of the venous column.

Of these powers the pressure of the atmosphere is, by far, the most intense in its degree, the most constant in its influence, and the most unvarying in its amount. It is that without which the circulation could not be maintained beyond a few moments.

The 'quiescent living animal' was a neat phrase, but to say that the pressure of the atmosphere might be 'entirely taken off' around the cavae and that the 'circulation could not be maintained beyond a few moments' without this pressure gradient were indefensible exaggerations which may have contributed to Barry's eclipse regardless of the fundamental value of his work.

With obvious relish, Barry was only too pleased to provide a translation of the Commissioners' Report in the English edition of his work-in spite of their criticism of some of his interpretations and his failure to recognize, or rather 


\section{Sir David Barry's Experiments on Venous Return}

admit, the inaccessibility of the pulmonary circulation. His experiments using his 'ingenious apparatus contrived for the purpose constantly succeeded', and 'his researches made in the very best spirit . . . were eminently calculated to elucidate' the physiology of the venous circulation. At the same time, Cuvier and Dumeril pointed out that the act of inspiration could not be held to 'explain the motion of blood in the veins of fishes' and some reptiles, 'for in these animals inspiration is a species of deglutition' unassociated with the arrival of venous blood at the heart, a fact in open contradiction to Barry's generalization 'that the blood which runs contrary to its own gravity, arrives at the heart only during inspiration' (Barry's italics). In his monumental encyclopedia Johannes Müller ${ }^{21}$ took the same line in objecting to the omnipotence of the intrathoracic negative pressure in accounting for venous return of blood to the heart, and cited the added stumbling-block of the circulation in the foetus. In the meantime, Poiseuille ${ }^{22}$ had developed the glass U-tube manometer to examine venous pressure and, although Barry 'estimated too highly the influence of inspiration on the motion of the blood', Müller admitted that Poiseuille's experiments 'confirmed Barry's opinion that during inspiration the venous blood of the body is drawn into the venous trunks in the thorax'. (In his second edition (184I) Müller corrected the confusion which arose in the first between Barry and Caleb Hillier Parry -Parry's An Experimental Inquiry into the Nature, Cause and Varieties of the Arterial Pulse, published in Bath in 1816, was translated into German (Uber die Ursache des arter. Pulses, Hanover, 1817 ) and in the discussion of Barry's work in the earlier edition Parry's name was used throughout in error.

For all his wrathful indignation, Carson ${ }^{13}$ was the first to pinpoint uno ictu Barry's fundamental error and his original contribution:

Sir David Barry is wrong in supposing, as he seems to do, that what is called, for want of better language, a vacuum, exists in the chest only during inspiration. The causes, by which it is produced, operate at all times, though not with the same force. For the lungs are always dilated, in the second state of the system, far beyond their natural conditions. It is only in consequence of the elasticity of the lungs that the vacuum, discovered by the experiments of Barry, could be produced. If the lungs had not been elastic, but dilatable like a bag, the windpipe would readily have supplied all the matter requisite to fill the chest during inspiration.

Had Barry realized, as did Carson, that inspiration simply increased the pressure gradient into the thorax he might not have made inspiration prepotent in promoting venous return; but 'discovered by the experiments of Barry' is a striking admission - one favourable phrase from a foe outweighs by far a library of praises furnished by friends. Whence sprang, one may ask, the 'sudden, extensive, and high reputation' that so nettled Carson? The explanation is to be found, it would seem, in Laennec's eulogy, ${ }^{23}$ included in the second edition of the immortal On Mediate Auscultation, which appeared the year after Barry's experiments were performed:

... Having myself witnessed several of Dr. Barry's experiments, I am convinced of the correctness of his opinion respecting the influence of atmospheric pressure on the circulation in the veins; and I consider his discovery as the most remarkable addition that has been made to that of his illustrious countryman, Harvey. ... 


\section{S. Breathnach}

\section{ACKNO WLEDGEMENTS}

I should like to thank Dr. D. H. Barron and the Staff of the Historical Library at Yale University School of Medicine for help and encouragement in the preparation of this paper.

\section{REFERENCES}

I. Robinson, V., Pathfinders in Medicine, New York, Medical Life Press, I929, pp. $355-6$.

2. FrankLIN, K. J., A Short History of Physiology, London, John Bale \& Danielsson, I933, p. 75 .

3. Ha r vey, W., De Motu Cordis, I628, cap. ii (cited by Barry, p. 37).

4. Hooke, R., Phil. Trans., 1667, 2, 539-40; Philosophical Transactions abridged by John Lawthrop, 5th ed., London, I 749, vol. III, pt. I, pp. 67-8.

5. Lowe R, R., Tractus de Corde, 1669, facsimile edition prefaced by an introduction and translation by K. J. Franklin and published as vol. Ix of Early Science in Oxford, ed. by R. T. Gunther, Oxford, University Press, 1932, pp. I I $5^{-1} 7$, $133,167-71$.

6. Foster, M., Lectures on the History of Physiology, Cambridge, University Press, r9or, pp. 14-15, 38-40.

7. BARRY, D., Experimental Researches on the Influence Exercised by Atmospheric Pressure upon the Progression of the Blood in the Veins, etc., London, T. \& G. Underwood, I826, pp. 3, 9-10, 20, 23, 33, 35, 38, 52-8, 63-5, 72-3. The first part of this work-the Memoir, Recherchés expérimentales sur la cause du mouvement du sang-was published in Paris, 1825 .

8. MorgagNi, J. B., De sedibus et causis morborum per anatomen indagatis, Venetus, ex Typographia Remondiniana, I 76I, Tom. I, Lib. II, epist. Anat. Med. XIX, art. 33-4, p. 183. Translated by B. Alexander, London, 1769; reprinted for New York Academy of Medicine, New York, Hafner, 196o, vol. I, p. 5 19.

9. HAles, S., Statical Essays containing Haemastaticks, etc., 3rd ed., London, Wilson and Nicol, I 733; experiments III and VII, reprinted by F. A. Willius and T. E. Keys in Cardiac Classics, St. Louis, Mosby, 1941, pp. 136, 142-4.

10. Halle R, A. von, Elementa physiologiae corporis humani, Lausanne, S. D'Amay, 1747. First Lines of Physiology, trans. and reprinted under the inspection of William Cullen, Edinburgh, C. Elliot, pp. I02, 162, I66.

I 1. - A Dissertation on the Motion of the Blood and the Effects of Bleeding, trans. by a Physician, London, J. Whiston and B. White, I 757, pp. 6o, 62, 63, 64, 74, 106.

12. Magendie, F., Fournal de Physiologie Experimentale, Paris, Mequignon-Marvis, I82 I, vol. I, p. I 36. Cited verbatim in The Physiology of Man, trans. by A. Flint, Jr., New York, Appleton, vol. I, p. 320.

13. Carson, J., An Inquiry into the Causes of Respiration: of the Motion of the Blood: Animal Heat: Absorption and Muscular Motion: with Practical Inferences, 2nd ed., London, Longman, Rees, Ormer, Brown, Green and Longman, I833, pp. I35, 208.

14. On the elasticity of the lungs, Phil. Trans., 1820, pp. 29-44.

I5. BREGHE R, G. A., Venous Return, New York, Grune and Stratton, 1956, pp. 104-7.

16. Magendie, F., Précis Elementaire de Physiologie, Paris, Mequignon-Marvis, i 817, vol. II, pp. 224, 323-4. Trans. by E. Milligan, An Elementary Compendium of Physiology, Philadelphia, J. Webster, pp. 309, 328-9.

17. Singe R, C., Galen on Anatomical Procedures, London, Oxford University Press for Wellcome Historical Medical Museum, 1956, Book VII, chap. 14, paras. 636-8, pp. 194-5. 


\section{Sir David Barry's Experiments on Venous Return}

18. Gournand, A., Ranges, H. A., Catheterization of the right auricle in man, Proc. Soc. exp. Biol. (N.Y.), 46, 1941, 462.

19. S Ghleier, J., Der Energievebrauch in der Blutbahn, Pflïgers Arch. ges. Physiol., I918, 173, 172 .

20. SJOstrand, T., Volume and distribution of blood, and their significance in regulating the circulation, Physiol. Rev., 1953, 33, 202-28.

21. Mǘl er, J., Handbuch der Physiologie des Menschen, Coblenz, J. Holscher, I838, vol. I, pp. 235-6. Trans. by W. Baly, Elements of Physiology, London, Taylor and Walton, 1838, vol. I, pp. 235-6. (In the second German edition, 1841, Barry's name is given correctly on $\mathrm{pp.}$. $183-4$.

22. Poise uille, J. L.-M., Recherches sur les causes du mouvement du sang dans les veines, 7. Univ. et Hebd. de Méd., Paris, 1830, 1, 289; 1831, 3, 97.

23. Laenne G, R. T. H., Traité de l'Auscultation médiate, 2nd ed., Paris, J. S. Chaudé, 1826, vol. II, pp. 4I5-16. Trans. with notes, by John Forbes, $A$ Treatise on the Diseases of the Chest and Mediate Auscultation, London, T. and G. Underwood, I827, pt. 3, bk. I, chap. IV, p. 554 . 